\title{
Diversified Agglomeration, Specialized Agglomeration and Innovation Efficiency of Pharmaceutical Manufacturing
}

\author{
Jinhuan Shi \\ Nanjing Normal University, Nanjing, China \\ Email: a1123539757@126.com
}

How to cite this paper: Shi, J.H. (2019) Diversified Agglomeration, Specialized Agglomeration and Innovation Efficiency of Pharmaceutical Manufacturing. Open Journal of Social Sciences, 7, 147-158. https://doi.org/10.4236/jss.2019.77014

Received: June 20, 2019

Accepted: July 20, 2019

Published: July 23, 2019

Copyright $\odot 2019$ by author(s) and Scientific Research Publishing Inc. This work is licensed under the Creative Commons Attribution International License (CC BY 4.0).

http://creativecommons.org/licenses/by/4.0/

\section{c) (i) Open Access}

\begin{abstract}
Based on the panel data of 31 provinces in China from 2009 to 2016, this paper uses DEA model and panel Tobit regression method to estimate and test the effect of diversified agglomeration and specialized agglomeration on the innovation efficiency of pharmaceutical manufacturing. The results show that diversified agglomeration significantly improves the innovation efficiency of pharmaceutical manufacturing industry. Specialized agglomeration is obviously not conducive to the improvement of innovation efficiency of pharmaceutical manufacturing industry; management capacity, innovation institution penetration rate and government innovation subsidies all significantly promote the innovation efficiency of pharmaceutical manufacturing industry. The effect of cooperative innovation intensity and industrial structure on the innovation efficiency of pharmaceutical manufacturing industry is not obvious.
\end{abstract}

\section{Keywords}

Specialized Agglomeration, Diversified Agglomeration, Innovation Efficiency, DEA-Tobit

\section{Problem Proposal and Literature Review}

Agglomeration is an important form of organization that promotes industrial innovation and upgrading. With the deepening of agglomeration research, the industrial clusters that have been generalized have been refined into diverse agglomerations and specialized agglomerations. Diversified agglomeration means that enterprises from different industries are concentrated in a certain geographical space [1]. Specialized agglomeration refers to the accumulation of sim- 
ilar enterprises in a certain geographical space [2]. At present, the academic community generally believes that the two agglomeration models have great differences in the path and impact of industrial innovation. Yang and Li believe that diversified agglomeration can promote innovation by optimizing industrial structure and rationally arranging industries [3]. Liu and Wang believe that diversified agglomeration provides cross-industry technical support, strengthens the integration of knowledge and technology in different fields, promotes innovative thinking, and is more conducive to innovation than specialized agglomeration [4]. At the same time, $\mathrm{Lu}$ and others believe that specialized agglomeration strengthens the exchange of similar innovation subjects, generates technological spillovers, and promotes innovation [5]. Zhu believes that professional agglomeration attracts high-level innovative talents, strengthens technology and knowledge spillovers, and is significantly conducive to innovation [6]. Moreover, the role of specialized agglomeration for enterprises to save the cost of innovation factors and strengthen the dissemination of silent information has been widely recognized. Cheng and Liu believe that enterprises in specialized clusters can feel the fierce competition in the market, which will promote enterprises to reduce production costs and increase labor productivity, and promote enterprises to upgrade and innovate technology [7]. From the research conclusions, Chai and Xiang [8], Lu and Shang [9] all believe that specialized agglomeration is more conducive to innovation and efficiency improvement than diversified agglomeration; Zhang and Zhao [10], Peng and Jiang [11], Hong [12] both believe that specialized agglomeration is not conducive to innovation, while diversified agglomeration promotes innovation [13]. From the above literature analysis, it is known that the effects of diversified agglomeration and specialized agglomeration on industrial innovation have not formed a consistent conclusion. This may be due to differences in research objects and agglomeration patterns that favor industrial innovation. Then, in the pharmaceutical manufacturing industry, which is related to the national health but is rarely studied, what kind of agglomeration model is more suitable for industrial innovation? This is the question that this article tries to answer, and it is also the research topic of this article.

Another striking innovation in this paper is that in the literature on the effects of diversified agglomeration and specialized agglomeration innovations, there are more research on innovative output, such as the value of new product output and the number of patent applications. But there are less research focusing on the study of innovation efficiency. Innovation efficiency is the ratio of innovation output to corresponding input of innovative production factors in a given time. Under the national accelerated development goal, attaching importance to the issue of innovation efficiency and improving the utilization rate of innovative resources is an objective need to accelerate the advancement of technology. In addition, the key reason why this paper chooses pharmaceutical manufacturing industry rather than other industries as research objects is that the progress 
and innovation of pharmaceutical manufacturing industry is related to national health. The development and production of new medicines guarantee people's healthy living and work, which is a prerequisite for the rapid development of China's economy. It is of great significance to pay attention to the innovation efficiency of the pharmaceutical manufacturing industry. Therefore, based on panel data of 31 provinces in China from 2009 to 2016, this paper uses DEA model and panel Tobit regression method to estimate and test the effect of diversified agglomeration and specialized agglomeration on the innovation efficiency of pharmaceutical manufacturing. The research in this paper will help pharmaceutical manufacturing enterprises to gather in the best mode, achieve optimal innovation resource allocation, and achieve maximum innovation output under the established innovation investment. These will optimize the innovation efficiency of pharmaceutical manufacturing industry. Innovative medicines which are produced at the fastest speed will further protect Chinese residents from overcoming the threat of illness, living and working healthily, thus promoting the accelerated development of the Chinese economy.

\section{Impact Mechanism Analysis}

1) Diversified agglomeration and innovation efficiency of pharmaceutical manufacturing

First of all, in terms of the innovation efficiency of pharmaceutical manufacturing industry measured by the commonly used input and output, the factors affecting the innovation efficiency of pharmaceutical manufacturing industry fall into two categories, one is the saving of innovation investment in pharmaceutical manufacturing industry, and the other is the growth of innovative output of pharmaceutical manufacturing industry [14]. Then, we will mainly analyze the process and mechanism of diversified agglomeration affecting the innovation efficiency of pharmaceutical manufacturing industry from these two aspects.

First, about the savings in innovation investment in the pharmaceutical manufacturing industry. The savings in innovation investment in the pharmaceutical manufacturing industry in the diversified agglomeration areas are mainly reflected in the efficiency of the use of innovative resources. The innovative resource allocation of pharmaceutical manufacturing enterprises in diversified agglomeration areas is more autonomous, flexible and efficient [15]. What's more, using different but related knowledge improves production technology and management level, make processes upgrade, achieve the efficiency of resource allocation, reduce the investment in innovation required for a given innovation. At last, it will achieve savings in innovative investment in pharmaceutical manufacturing. Second, about the growth of innovation output in the pharmaceutical manufacturing industry. Compared with the specialized agglomeration area, the growth of the innovation output of the pharmaceutical manufacturing industry in the diversified agglomeration area is mainly reflected in the success probability of product innovation. In the diversified agglomeration area, pharmaceutical manufacturing enterprises benefit from the technological environ- 
ment with greater knowledge width and technical potential [3], which is less affected by the lock-up of specialized agglomeration [16], and enhances the innovation of pharmaceutical manufacturing products as a whole. The probability of success is to achieve the growth of innovative output in the pharmaceutical manufacturing industry. However, the development of things has two sides. The higher the degree of diversification, the higher the investment in innovation in the pharmaceutical industry may be. In the diversified agglomeration area, the technical thresholds of non-similar enterprises are large, the cost of cooperative innovation is high, and the cost of talent and capital flows is large. They will all contribute to increasing the investment in innovation in pharmaceutical manufacturing.

2) Specialized agglomeration and innovation efficiency of pharmaceutical manufacturing

Specialized agglomeration also affects the innovation efficiency of pharmaceutical manufacturing through the two channels of savings in innovation in pharmaceutical manufacturing and growth in innovation in pharmaceutical manufacturing.

First, about the savings in innovation in pharmaceutical manufacturing. Compared with diversified agglomeration areas, specialized agglomeration affects the savings of innovation in pharmaceutical manufacturing from two aspects, one is capital, and the other is labor. The savings of specialized agglomeration on capital are mainly reflected in the cost of capital use. In the case of designated innovations, pharmaceutical manufacturing companies located in specialized clusters require less capital. This is because, compared to non-aggregated areas, pharmaceutical manufacturers in the agglomeration area have lower prices for collecting and acquiring innovation-related information, lower prices for public infrastructure [17], and lower prices for purchasing innovative elements. The price of obtaining external capital is also lower [18]. The concentration of specialized agglomeration on labor is mainly reflected in the improvement of human capital. Labor has investment value, and high levels of human capital have higher labor productivity than low-level human capital. Specialized agglomeration promotes the quality of labor. Technology and management experience through knowledge spillover. They raise the level of human capital, reduce the low level of human capital and the number of machines required for established innovation. In particular, high levels of human capital can accomplish innovative work that takes less time and can't be completed with low levels of human capital. Thus, when the degree of specialized concentration is strengthened, pharmaceutical manufacturers usually only need less capital and labor input to obtain the established innovation. The savings on the cost of innovation resources translates into savings in innovation inputs, and reductions in innovation inputs under established innovation outputs, thereby enabling improvements in the innovation efficiency of pharmaceutical manufacturing.

Second, about the growth of innovation output in the pharmaceutical manufacturing industry. The growth of innovation output in the pharmaceutical 
manufacturing industry has two meanings, one is the increase of direct innovation output, such as patents and new products; the other is the transformation and industrialization of innovation results. Innovation is a high-risk production activity. With high-yield but no guarantees, only large pharmaceutical manufacturers have the motivation and ability to innovate. In reality, pharmaceutical manufacturing companies in non-aggregated areas are usually engaged in simple imitation and restructuring of pharmaceutical products, and high-profit enterprises that are in a leading position in the pharmaceutical manufacturing market usually come from gathering areas. The lack of innovative information and role models limits the participation of non-aggregate companies in innovative production. Therefore, the accumulation of pharmaceutical manufacturing enterprises is first of all to stimulate the innovation motivation and willingness of enterprises [19], and promote the participation of pharmaceutical manufacturing enterprises in the innovation production process, so as to achieve the growth of innovation output. On the other hand, the level of patent protection in the agglomeration area [20] and the development of the technology market [21] are significantly better and faster than the non-aggregation areas. They play an important role in the transformation and industrialization of innovation achievements in pharmaceutical manufacturing enterprises. They are conducive to the increase in innovation output. However, there are also views that the degree of specialization is too high, and its negative crowding effect will reduce the innovation efficiency of the pharmaceutical manufacturing industry [22], that is, under the premise of innovation factors and land air supply, excessive professional concentration is likely to cause input costs. The increase and deterioration of the ecological environment [23] have led to the escape of high-level innovation elements, which has made the innovation and efficiency of the pharmaceutical manufacturing industry less efficient.

\section{Model Setting and Variable Selection}

In the empirical part, we will first use the DEA model method to measure the innovation efficiency of the pharmaceutical manufacturing industry, and then use the panel Tobit regression method to test the impact of diversified agglomeration and specialized agglomeration on the innovation efficiency of the pharmaceutical manufacturing industry.

1) DEA model

The most commonly used methods for measuring efficiency are the stochastic frontier method and the DEA model method. The difference between the DEA model method and the stochastic frontier method is that the stochastic frontier model method can only measure the innovation efficiency of multi-input single-output, while the DEA model method can measure the innovation efficiency of multi-input and multi-output. Due to the comprehensive consideration of diverse innovation outputs, many scholars choose to use the DEA model [13] [16] [19]. Drawing on their approach, this paper will also use the DEA model to 
measure the innovation efficiency of the pharmaceutical industry. The DEA model is specifically set as follows:

$$
D_{B C^{2}}\left\{\begin{array}{l}
\min _{\vartheta, \lambda}\left[\theta-\varepsilon\left(e^{t} s^{-}+e^{t} s^{+}\right)\right] \\
\sum_{j=1}^{n} x_{i j} \lambda_{j}+s^{+}=\theta x_{o i} \\
\sum_{j=1}^{n} y_{j r} \lambda_{j}-s^{+}=y_{o r} \\
\sum_{j=1}^{n} \lambda_{j}=1 \\
s^{+} \geq 0, s^{-} \geq 0
\end{array}\right.
$$

Finally, the value of the innovation efficiency of the pharmaceutical manufacturing industry will be in the $0-1$ range. The larger the value, the higher the efficiency. The innovation efficiency of the pharmaceutical manufacturing industry will also be divided into scale efficiency and technical efficiency to explore whether the improvement of efficiency comes from the expansion of scale or the advancement of technology.

2) Panel Tobit regression

The general model of the panel Tobit is as follows:

$$
y_{i t}=x_{i t}^{\prime} \beta+\mu_{i}+\varepsilon_{i t}
$$

$y_{i t}$ is the interpreted variable, $x_{i t}$, which is the explanatory variable and the control variable, $\beta$ is the variable coefficient, $\mu_{i}$ is the individual effect, and the disturbance term $\varepsilon_{i t} \sim N\left(0, \sigma_{\varepsilon}^{2}\right)$.

3) Indicator selection

The explanatory variable is the innovation efficiency of the pharmaceutical manufacturing industry. The output value of the new products in the pharmaceutical manufacturing industry and the number of patent applications represent the innovation output. The R\&D personnel in the pharmaceutical manufacturing industry are equivalent to the full-time equivalent and the $R \& D$ expenditure internal expenditure represents the innovation investment. The innovation efficiency of the pharmaceutical manufacturing industry is calculated through the DEA model method.

Interpretative variables are diverse agglomerations and specialized agglomerations. Drawing on the practice of $\mathrm{He}$ [24] and others, the calculation method of diversified agglomeration is that the proportion of high-tech industries other than pharmaceutical manufacturing industry in a certain area is reduced by the proportion of employment in the country, and the absolute value is summed to The reciprocal of the sum is used to measure diversification; the proportion of occupational agglomeration in the pharmaceutical industry in the region is divided by its national share.

Control variables choose business management capabilities, innovation institution penetration rate, cooperation innovation intensity, government innovation subsidies and industrial structure. The management and management ability is measured by the ratio of the profit of the pharmaceutical manufacturing 
industry to the income of its main business. The penetration rate of the innovation institution is measured by the ratio of the number of pharmaceutical manufacturing enterprises with the innovative research and development institutions to the total number of pharmaceutical manufacturing enterprises. The external expenditure of R\&D expenditure in the pharmaceutical manufacturing industry is measured by the ratio of the internal expenditure of $\mathrm{R} \& \mathrm{D}$ funds. The government innovation subsidies are measured by the proportion of government funds in the internal expenditure of $\mathrm{R} \& \mathrm{D}$ funds, and the industrial structure is measured by the proportion of the added value of the secondary industry to GDP.

The panel data includes 31 provincial-level regions in mainland China. The data comes from the 2009-2016 China High-Tech Industry Statistical Yearbook, China Statistical Yearbook and WPS Data Platform. Table 1 reports the basic statistical characteristics of the variables.

\section{Empirical Estimation Result}

1) General estimation results

Firstly, for the panel model of the merged data, the mixed Tobit regression is performed using the clustering robust standard error. Secondly, for the fixed-effect Tobit model, the conditional maximum likelihood estimation cannot be performed because the sufficient statistics of individual heterogeneity cannot be found. If the dummy variables of the panel unit are added directly to the mixed Tobit regression, the resulting fixed effect estimates are also inconsistent. Therefore, in general, only the Tobit model of random effects is considered. As for whether you should choose mixed regression or random effects. Table 2 shows that the LR test rejects the null hypothesis of mixed regression at the significance level of 0.05 , so it is considered that there is an individual effect, and the Tobit regression model of random effects should be used.

Table 1. Basic statistical characteristics of variables.

\begin{tabular}{|c|c|c|c|c|c|}
\hline $\begin{array}{l}\text { Variable } \\
\text { Type }\end{array}$ & Variable & Ave & Min & $\operatorname{Max}$ & $\begin{array}{l}\text { Standard } \\
\text { deviation }\end{array}$ \\
\hline $\begin{array}{l}\text { Explanated } \\
\text { variable }\end{array}$ & $\begin{array}{l}\text { pharmaceutical manufacturing } \\
\text { innovation efficiency }\end{array}$ & 0.5042 & 0.0260 & 1.0000 & 0.2642 \\
\hline \multirow{4}{*}{$\begin{array}{l}\text { Explanatory } \\
\text { variables }\end{array}$} & Diversified agglomeration & 3.2125 & 0.9173 & 12.6766 & 2.1689 \\
\hline & Specialized agglomeration & 2.5144 & 0.1825 & 6.4511 & 1.6731 \\
\hline & management capacity & 0.1211 & 0.0000 & 0.4176 & 0.0537 \\
\hline & $\begin{array}{l}\text { Innovative institution } \\
\text { penetration rate }\end{array}$ & 0.2500 & 0.0385 & 0.7778 & 0.1302 \\
\hline \multirow[t]{3}{*}{$\begin{array}{l}\text { Control } \\
\text { variable }\end{array}$} & $\begin{array}{l}\text { Cooperative innovation } \\
\text { intensity }\end{array}$ & 0.1511 & 0.000 & 1.1447 & 0.1315 \\
\hline & $\begin{array}{l}\text { Government Innovation } \\
\text { Subsidy }\end{array}$ & 0.0711 & 0.0000 & 0.3894 & 0.0498 \\
\hline & Industrial structure & 0.4632 & 0.1926 & 0.5900 & 0.0830 \\
\hline
\end{tabular}


Table 2. General estimation results.

\begin{tabular}{|c|c|c|c|c|c|c|}
\hline & \multicolumn{2}{|c|}{ Innovation efficiency } & \multicolumn{2}{|c|}{ technical efficiency } & \multicolumn{2}{|c|}{ scale efficiency } \\
\hline & mixed & random & mixed & random & mixed & random \\
\hline \multirow[t]{2}{*}{ Div agg } & $0.0123^{* *}$ & $0.0093^{* * *}$ & $0.0207^{* *}$ & $0.0119^{* * *}$ & $0.0019^{* *}$ & $0.0033^{* * *}$ \\
\hline & 0.0097 & 0.0111 & 0.0087 & 0.0115 & 0.0095 & 0.0102 \\
\hline \multirow[t]{2}{*}{ Spe agg } & $-0.0059^{* * *}$ & $-0.0148^{* * *}$ & -0.0146 & $-0.0190^{* *}$ & $-0.0020^{*}$ & $-0.0036^{* *}$ \\
\hline & 0.0129 & 0.0169 & 0.0116 & 0.0186 & 0.0127 & 0.0135 \\
\hline \multirow[t]{2}{*}{ Man abi } & $0.2211^{* *}$ & $0.2848^{* * *}$ & $0.2013^{* *}$ & $0.3592^{* * *}$ & $0.3006^{* *}$ & $0.2782^{* * *}$ \\
\hline & 0.3776 & 0.4735 & 0.3361 & 0.5147 & 0.3685 & 0.3940 \\
\hline \multirow[t]{2}{*}{ Inn ins } & $0.1745^{* *}$ & $0.2485^{* * *}$ & $0.3399^{* * *}$ & $0.4869^{* * *}$ & $0.5443^{* * *}$ & $0.5610^{* * *}$ \\
\hline & 0.1382 & 0.1646 & 0.1231 & 0.1760 & 0.1349 & 0.1437 \\
\hline \multirow[t]{2}{*}{ Coo inn } & -0.0513 & 0.0224 & 0.0374 & 0.1139 & -0.0696 & -0.0796 \\
\hline & 0.1377 & 0.1602 & 0.1226 & 0.1524 & 0.1344 & 0.1422 \\
\hline \multirow[t]{2}{*}{ Gov inn } & $0.0856^{* *}$ & $0.0505^{* *}$ & $0.1114^{* *}$ & $0.2702^{* * *}$ & $0.0001^{* * *}$ & $0.1486^{* * *}$ \\
\hline & 0.3546 & 0.4033 & 0.3156 & 0.3912 & 0.3460 & 0.3724 \\
\hline \multirow[t]{2}{*}{ Ind str } & -0.4459 & -0.7584 & 0.0129 & -0.0467 & $-0.7705^{*}$ & -0.7843 \\
\hline & 0.2494 & 0.3474 & 0.2220 & 0.3701 & 0.2434 & 0.2576 \\
\hline LR test & & 0.001 & & 0.000 & & 0.000 \\
\hline $\mathrm{R}^{2}$ & 0.0791 & & 0.8938 & & 0.0857 & \\
\hline
\end{tabular}

Note: ${ }^{*},{ }^{* *}{ }^{* *}$ indicate the significance test at $10 \%, 5 \%$, and $1 \%$, respectively.

The panel Tobit regression model's estimations of random effects are listed in Table 2. It shows that diversified agglomeration significantly promotes the innovation efficiency of pharmaceutical manufacturing at a significant level of 0.05 . Specialized agglomeration is significantly detrimental to the innovation efficiency of pharmaceutical manufacturing at a significant level of 0.001 . Further decomposing the innovation efficiency of pharmaceutical manufacturing into technical efficiency and scale efficiency, it is found that the direction of action of diversified agglomeration and professional agglomeration has not changed. Therefore, in order to improve the innovation efficiency of the pharmaceutical manufacturing industry, pharmaceutical manufacturing enterprises should carry out diversified agglomeration and make full use of the diversified knowledge spillovers in the agglomeration area to improve the innovation quality and quantity of the pharmaceutical manufacturing industry. Simultaneously, combined with the above analysis of the impact mechanism, we can see that diversified agglomeration improves the innovation efficiency of pharmaceutical manufacturing by saving innovation investment in pharmaceutical manufacturing and increasing the innovation output of pharmaceutical manufacturing. However, the excessive professionalization of pharmaceutical manufacturing has caused an increase in the cost of innovation input, leading to the escape of high-level innovation elements and reducing the innovation efficiency of pharmaceutical 
manufacturing.

From the perspective of control variables, the pharmaceutical manufacturing industry management ability is promoting the innovation efficiency of pharmaceutical manufacturing. If the industrial management ability is stronger, the choice of innovative projects will be more sensible. The supervision of innovative projects will be more comprehensive. The efficiency of innovation resource utilization will be higher, and they will contribute to the improvement of the innovation efficiency of the pharmaceutical manufacturing industry. Second, the innovation efficiency of the pharmaceutical manufacturing industry is also positively affected by the penetration rate of innovation institutions. This shows that the more companies that set up internal innovation institutions in the pharmaceutical manufacturing industry, the more efficient the innovation efficiency of the pharmaceutical manufacturing industry. Obviously, the establishment of innovative institutions within the enterprise will be conducive to the efficient allocation of innovative resources for a single enterprise. The more innovative institutions within the enterprise will effectively improve the innovation efficiency of an industry. Then, the government's innovation subsidies are also actively promoting the innovation efficiency of the pharmaceutical manufacturing industry. On the other hand, the impact of the strength of cooperation between enterprises in the pharmaceutical manufacturing industry and other innovative entities on the innovation efficiency of pharmaceutical manufacturing industry is not significant, and the effect of the industrial structure of the gathering place on the innovation efficiency of the pharmaceutical manufacturing industry is also not significant. By summarizing the direction of the role of control variables in the innovation efficiency of pharmaceutical manufacturing, it is known that business management capabilities, innovation institution penetration rate and government innovation subsidies have significantly promoted the innovation efficiency of pharmaceutical manufacturing, while the intensity of cooperative innovation and industrial structure have contributed to the innovation efficiency of pharmaceutical manufacturing. The effect is not obvious.

2) Robustness test

In this paper, the sample segmentation and substitution variables are used to test the robustness in Table 3: First, sample segmentation. The data of 31 provinces and cities in 2009 were removed, and the Tobit regression method was used again to estimate the effect of diversified agglomeration and specialized agglomeration on the innovation efficiency of pharmaceutical manufacturing. Second, replace the variable. Use production value instead of employment to measure diversified agglomeration and specialized agglomeration. The test results are shown in Table 3. Although the sizes of the diversified agglomeration and the specialized agglomeration coefficients have changed, the sign of the coefficients has not changed, and its significance remains unchanged or even more significant. This shows that the conclusion of this paper is that diversified agglomeration significantly promotes the innovation efficiency of pharmaceutical 
Table 3. Results of the robustness test.

\begin{tabular}{ccccccc}
\hline & \multicolumn{3}{c}{ Sample segmentation } & \multicolumn{3}{c}{ Variable substitution } \\
\hline & Inn eff & tec eff & sca eff & Inn eff & tec eff & sca eff \\
\hline Div agg & $0.0160^{* * *}$ & $0.0138^{* * *}$ & $0.0083^{* * *}$ & $0.0156^{* * *}$ & $0.0149^{* * *}$ & $0.0115^{* * *}$ \\
& 0.0115 & 0.0120 & 0.0109 & 0.0119 & 0.0117 & 0.0115 \\
Spe agg & $-0.0100^{* * *}$ & $-0.0149^{* * *}$ & $-0.0035^{* * *}$ & $-0.0068^{* * *}$ & $-0.0023^{* * *}$ & $-0.0089^{* * *}$ \\
& 0.0166 & 0.0188 & 0.0145 & 0.0177 & 0.0193 & 0.0156 \\
Man abi & $0.2036^{* * *}$ & $0.6345^{* * *}$ & $0.2860^{* * *}$ & $0.2682^{* * *}$ & $0.8299^{* * *}$ & $0.2134^{* * *}$ \\
& 0.4873 & 0.5592 & 0.4393 & 0.5396 & 0.5867 & 0.4757 \\
Inn ins & $0.2604^{* * *}$ & $0.4647^{* * *}$ & $0.6017^{* * *}$ & $0.2036^{* * *}$ & $0.5208^{* * *}$ & $0.5473^{* * *}$ \\
& 0.1618 & 0.1754 & 0.1517 & 0.1658 & 0.1751 & 0.1541 \\
Coo inn & -0.0934 & 0.0335 & -0.1239 & -0.0634 & 0.0429 & -0.0894 \\
& 0.1605 & 0.1548 & 0.1502 & 0.1639 & 0.1506 & 0.1530 \\
Gov inn & $0.0771^{* * *}$ & $0.8118^{* * *}$ & $0.1048^{* * *}$ & $0.1560^{* * *}$ & $0.9454^{* * *}$ & $0.0317^{* * *}$ \\
& 0.4261 & 0.4292 & 0.4091 & 0.4879 & 0.4538 & 0.4786 \\
LR test & 0.000 & 0.000 & 0.002 & 0.044 & 0.000 & 0.000 \\
\hline
\end{tabular}

Note: ${ }^{*}{ }^{* *},{ }^{* *}$ respectively indicate the significance test at the $10 \%, 5 \%$, and $1 \%$ levels.

manufacturing industry. Specialized agglomeration is obviously not conducive to the improvement of innovation efficiency of pharmaceutical manufacturing industry, and has certain credibility. Two robustness tests have also confirmed: management and management capabilities, innovation institution penetration rate and government innovation subsidies all significantly promote the innovation efficiency of pharmaceutical manufacturing industry, while the intensity of cooperative innovation and industrial structure have no obvious effect on the innovation efficiency of pharmaceutical manufacturing industry.

\section{Research Conclusions and Policy Recommendations}

This paper makes a systematic analysis of the impact of diversified agglomeration and specialized agglomeration on the innovation efficiency of pharmaceutical manufacturing industry by using the data of various provinces and cities in China from 2009 to 2016. The research shows that diversified agglomeration significantly improves the innovation efficiency and professionalization of pharmaceutical manufacturing. Agglomeration is obviously not conducive to the improvement of innovation efficiency in pharmaceutical manufacturing industry; management and management capabilities, innovation institution penetration rate and government innovation subsidies all significantly promote the innovation efficiency of pharmaceutical manufacturing industry, while the intensity of cooperative innovation and industrial structure have no obvious effect on 
the innovation efficiency of pharmaceutical manufacturing industry. Therefore, we believe that the innovation efficiency of pharmaceutical manufacturing can be improved from the following aspects: First, guide the pharmaceutical manufacturing enterprises to achieve diversified agglomeration and improve the innovation efficiency of pharmaceutical manufacturing. Further, the government should guide the pharmaceutical manufacturing enterprises to be moderately dispersed, and then the adverse effects of excessive professional concentration are weakened. Second, we should effectively use other key elements in promoting the improvement of innovation efficiency in pharmaceutical manufacturing. For example, it is important for the pharmaceutical manufacturing enterprises to improve their management capabilities, optimize innovative production processes, make full use of innovative production factors, save innovation costs, increase innovation output, and improve the innovation efficiency of pharmaceutical manufacturing industries. Then, the government should formulate incentive policies to encourage pharmaceutical manufacturing enterprises to set up scientific research institutions. The establishment of scientific research institutions will strengthen the research and development of enterprises, innovate and absorb the ability to innovate. Last but not least, the government needs to continue to increase incentives for innovation in the pharmaceutical manufacturing industry, and the three work together to promote innovation and efficiency improvement in the pharmaceutical manufacturing industry.

\section{Conflicts of Interest}

The author declares no conflicts of interest regarding the publication of this paper.

\section{References}

[1] Jacobs, J. (1969) The Economy of Cities. Vintage, New York.

[2] Marshall, A. (1920) Principles of Economics: An Introductory Volume. Eight Edition, The Macmillan Press, London.

[3] Yang, R.F. and Li, N. (2019) The Influence of Industrial Agglomeration on the High-Quality Development of the Yangtze River Economic Belt. Regional Economic Review, 2, 1-9.

[4] Liu, X.Y. and Wang, W. (2013) Agglomeration Economy and Enterprise Innovation-An Empirical Study Based on Panel Data of Chinese Manufacturing Enterprises. Industrial Economic Review, 12, 35-53.

[5] Lu, R.J., Hu, J. and Zhang, Y.M. (2019) The Mechanism of Production Service Industry Agglomeration on Regional Technology Transfer-From the Perspective of Collaborative Innovation and Environmental Regulation. Science and Technology Progress and Policy, 36, 51-58.

[6] Lei, Z. and Bang, N.J. (2007) International R\&D Spillovers: Trade, FDI, and Information Technology as Spillover Channels. Review of International Economics, 15, 955-976. https://doi.org/10.1111/j.1467-9396.2007.00691.x

[7] Cheng, Z.H. and Liu, J. (2015) Industrial Agglomeration, Space Spillover and Manufacturing Innovation-Based on Spatial Econometric Analysis of Chinese Urban Data. Journal of Shanxi University of Finance and Economics, 37, 34-44. 
[8] Chai, Z.X. and Xiang, H.J. (2010) The Influence of Structural Characteristics of Space Economy on Regional Innovation. Southern Economy, 3, 3-12.

[9] Lü, C.C., Shang, Y.Y. (2017) Research on Time and Space Effect of High-Tech Industry Agglomeration Model and Innovation Output. Management Science, 30, 64-79.

[10] Zhang, M.Q. and Zhao, Y.Y. (2008) The Impact of Industrial Agglomeration on Spatial Differences of Innovation Activities-An Empirical Study Based on Chinese Manufacturing Data. Statistics and Information Forum, 3, 43-47.

[11] Peng, X. and Jiang, C.H. (2011) Industrial Agglomeration, Knowledge Spillover and Regional Innovation-An Empirical Test Based on Chinese Industrial Industry. Economics (Quarterly), 10, 913-934.

[12] Hong, Q.L. (2010) Industrial Agglomeration and Regional Innovation Research. Wuhan University, Wuhan, 12-18.

[13] Chen, J., Liang, W. and Wu, H. (2013) Research on the Relationship between Industrial Agglomeration and Innovation Performance under the Background of Open Innovation-Taking China's High-Tech Industry as an Example. Science Research, 31, 623-629+577.

[14] Zhang, Z.D. and Wu, D. (2017) Advanced Human Capital Structure and Industrial Innovation Efficiency Improvement-Based on the Empirical Analysis of the Yangtze River Economic Belt. Contemporary Economic Management, 9, 1-12.

[15] Keeble, D., Lawson, C., Moore, B. and Wilkinson, F. (1999) Coective Learning Process, Netwoking and "Institutional Thickness" in the Cambridge Region. Regional Studies, 33, 295-303. https://doi.org/10.1080/00343409950081167

[16] Lu, C.C. (2016) Is the Specialization of High-Tech Industries in China More Conducive to Regional Industrial Innovation than Diversified Agglomeration? Research and Development Management, 6, 27-37.

[17] Zhang, G.N., Hong, G.Z. and Chen, G.H. (2014) Infrastructure, Space Spillover and Manufacturing Cost Effect. Economics (Quarterly), 13, 285-304.

[18] Sheng, D. and Wang, Y.J. (2013) Industrial Agglomeration, Credit Resource Allocation Efficiency and Corporate Financing Costs-Evidence from World Bank Survey Data and Chinese Industrial Enterprise Data. Management World, 6, 85-98.

[19] Li, S.S. and Ju, W.L. (2018) Can Industrial Agglomeration Promote Innovation in Manufacturing Enterprises? Research on Financial and Economic Issues, 4, 30-38.

[20] Xie, W. and $\mathrm{Bu}, \mathrm{W}$. (2018) High-Tech Industry Agglomeration and Innovation-Based on the Threshold Effect of Patent Protection. China Science and Technology Forum, 10, 111-119.

[21] Zhang, Y. and Lu, X.X. (2015) Regional Carbon Dioxide Emission Reduction Research from the Perspective of Technology Trading and Industrial Agglomeration-Evidence from China's Provincial Level. Finance and Trade Research, 26, 33-40.

[22] Li, J.X. and Song, D.Y. (2008) Specialized Agglomeration, Diversified Agglomeration and Urban Agglomeration Economy-An Empirical Study Based on Panel Data of Chinese Prefecture-Level Units. Management World, 2, 25-34.

[23] Yuan, Y.J. and Xie, R.H. (2015) The Intrinsic Relationship between Industrial Agglomeration, Technological Innovation and Environmental Pollution. Science Research, 33, 1340-1347.

[24] He, C.F. and Pan, F.H. (2009) Research on Urban Industrial Growth in China: Based on Dynamic Externality and Economic Transformation. Geographical Research, 28, 726-737. 